\title{
Suspect and Nontargeted Strategies to Investigate in Vitro Human Biotransformation Products of Emerging Environmental Contaminants: The Benzotriazoles
}

\author{
Christine Baduel, $*,+\ddagger$ Foon Yin Lai, ${ }^{\S}, \|$ Alexander L. N. van Nuijs, ${ }^{\S}$ and Adrian Covaci*, ${ }^{\S}$ \\ ${ }^{\dagger}$ Université Grenoble Alpes, IRD, CNRS, Grenoble INP, IGE, 38050 Grenoble, France \\ †Université Lyon, CNRS, Université Claude Bernard Lyon 1, ENS de Lyon, Institute of Analytical Sciences, UMR 5280, F-69100 \\ Villeurbanne, France

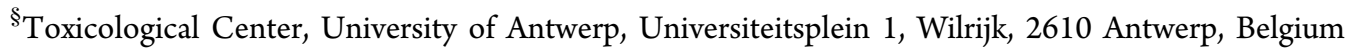 \\ "Department of Aquatic Sciences and Assessment, Swedish University of Agricultural Sciences (SLU), Box 7050, SE-750 07 \\ Uppsala, Sweden
}

Supporting Information

ABSTRACT: Benzotriazole derivatives (BTRs) are high production volume chemicals involved in a wide range of applications and consumer products resulting in their ubiquitous presence in environmental matrices. Yet, the human exposure assessment to these chemicals is limited since it is based only on the analysis of parent compounds in biological matrices. The objective of this study was to investigate the in vitro human biotransformation for three widely used BTRs and to stepwise examine the role of Phase I and II enzymes (cytochrome P450 (CYP), uridine glucuronic acid transferase (UGT), and sulfotransferase (SULT)) in their biotransformation. Extracts with generated biotransformation products (bioTPs) were analyzed using liquid chromatography coupled to quadrupole-

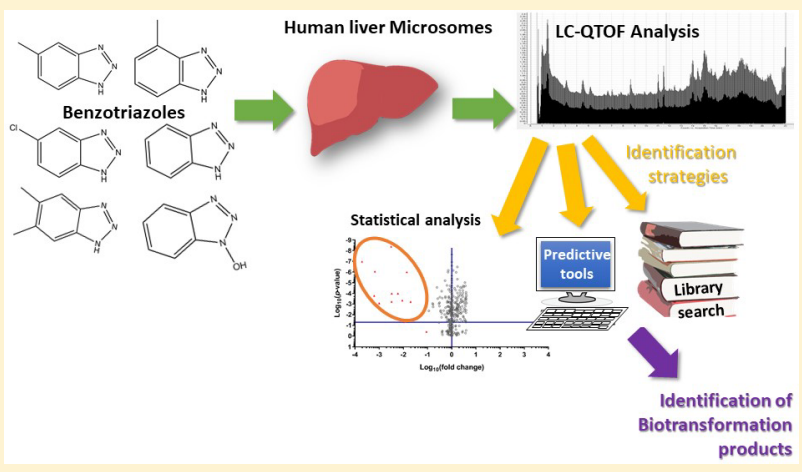
time-of-flight mass spectrometry (LC-QTOF-MS), followed by their identification based on a workflow combining suspect and nontargeted strategies. Ten bioTPs were identified for $1 \mathrm{H}$-benzotriazole, 14 for tolyltriazole, and 14 for 5 -chloro- $1 \mathrm{H}$ benzotriazole. Most of the proposed bioTPs were identified and structurally elucidated for the first time. Based on these findings, possible bioTPs and metabolic transformation pathways were subsequently predicted for other structurally close BTR derivatives. Our findings provide new identified in vitro biotransformation products for future biomonitoring studies and emphasize that it is important to investigate the biotransformation pathway to assess overall exposure to xenobiotics.

\section{INTRODUCTION}

$1 H$-Benzotriazole (1H-BTR) and its derivatives (collectively referred to as BTRs) are heterocyclic compounds containing two condensed rings (benzene and triazole). BTRs are built upon the parent moiety 1H-BTR (C6H5N3) with substitutions of different chemical groups, such as tolyltriazole (TTR, mixtures of 4- and 5-methyl-1H-BTR), 5-chloro-1H-benzotriazole (5-Cl-1H-BTR), 5,6-dimethyl-1H-benzotriazole (XTR), and hydroxy-benzotriazole (1-OH-BTR). BTRs, particularly $1 \mathrm{H}-\mathrm{BTR}$ and $\mathrm{TTR},{ }^{1-4}$ are extensively used as corrosion and flame inhibitors in different applications (e.g., antifreeze formulations, industrial cooling systems, hydraulic fluids). Some BTRs have also been used as lubricants and greases, washing and cleaning products, as well as UV stabilizers to reduce degradation and yellowing of materials (e.g., textiles, plastics, sports equipment, car components, etc.). ${ }^{2-4}$ With a wide range of applications, BTRs are high production volume (HPV) chemicals. Between 1000 and
10,000 tons of 1H-BTR are estimated to be manufactured and/or imported in the European economic area annually. ${ }^{1}$

Due to their extensive use, BTRs were found in different environmental matrices and consumer products. These compounds have been detected in tap water in China, Spain, ${ }^{6}$ and the $\mathrm{UK}^{7}$ with concentrations ranging from 0.7 to $310 \mathrm{ng} / \mathrm{L}$. BTRs were recently measured in indoor and outdoor air, in both vapor and particulate phases. ${ }^{8,9}$ The most frequently detected BTRs in air were 1H-BTR, TTR, and 5-ClBTR. BTRs were also omnipresent in indoor dust and across different countries (USA, China, Japan, and Korea), with a summed concentration of six BTRs ranging from 1 to $1980 \mathrm{ng} /$ g. TTR was the major BTR derivative measured in dust, followed by 5-Cl-BTR and 1H-BTR. ${ }^{10}$ BTRs were also found

Received: April 22, 2019

Revised: June 11, 2019

Accepted: June 16, 2019

Published: June 16, 2019 


\section{Experimental Set up}

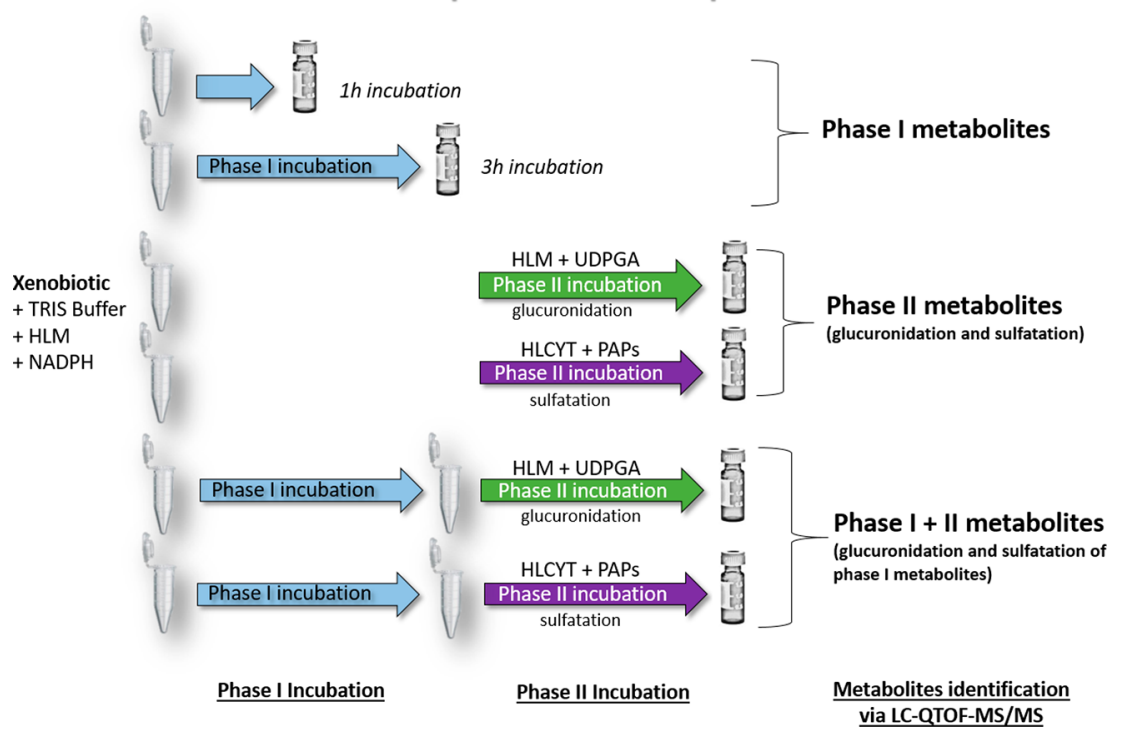

Figure 1. Overview in vitro metabolism assay.

in textile and a recent study has shown about $20 \%$ of the analyzed clothing contained TTR, 1H-BTR, and/or 5-ClBTR. $^{11,12}$ Elevated BTR levels were observed in some textiles, with the highest concentration measured for 1H-BTR (14 mg/ g) in graphically printed infant clothing. Printed graphics on clothes and socks have been proposed to account for a major proportion of the estimated exposure doses to BTRs. ${ }^{11}$

Their ubiquitous presence in a wide range of environmental media and in consumer products suggests a potential human exposure. The knowledge of human exposure to BTRs is still very limited, but human exposure has been evidenced through analysis of urine, ${ }^{13-17}$ adipose tissue, and amniotic fluid. ${ }^{13}$ Due to the lack of related bioTPs, only the analysis of parent compounds in biological matrices has been targeted. Parent BTRs were determined in human urine from general populations collected across seven countries. ${ }^{15,17}$ XTR followed by TTR and 1H-BTR were the BTR derivatives frequently detected and in higher levels from all five Asian countries compared to the U.S. and Greece, with the greatest total concentration of five BTRs measured at $24.5 \mathrm{ng} / \mathrm{mL} .^{15}$ The overall exposure however may not be fully assessed, as only one bioTP has been investigated in these studies. Only one study has shown a preliminary in vitro biotransformation of $1 \mathrm{H}-\mathrm{BTR}$ with rat liver microsomes revealing the presence of bioTPs. However, there remains a large knowledge gap on human biotransformation of BTRs.

While there is an increasing number of studies assessing environmental contamination and human exposure to BTRs, human bioTPs of BTRs remain unknown. To date, 1H-BTR has been classified as a suspected human carcinogen by the Dutch Expert Committee on Occupational Standards (Health Council of Netherlands), but toxicological effects of BTR derivatives on humans are still unavailable. The widespread use of BTRs and their occurrence in a wide range of environmental media (drinking water, indoor and outdoor air, indoor dust, textiles, etc.) as well as human urine samples across different countries suggest that the population is exposed continuously to these chemicals worldwide. Hence, there is a growing need to identify if there are relevant biomarkers for further studies of human exposure to BTRs.
The objective of this study was to investigate in vitro human biotransformation of BTRs. With human liver microsomes and cytosol fractions, we aimed to stepwise examine the role of Phase I and II enzymes (cytochrome P450 (CYP), uridine glucuronic acid transferase (UGT), and sulfotransferase (SULT)) in the biotransformation of BTRs. This resulted in a set of Phase I and Phase II bioTPs, which allowed us to propose potential biomarkers for future biomonitoring studies. Being highly used and ubiquitous, 1H-BTR, 4-TTR, and 5-ClBTR were selected as the subtrates in the present study. Moreover, they could be considered as model compounds to predict potential bioTPs of other widely used BTRs derivatives (i.e., 5-TTR, XTR, and OH-BTR). Generated bioTPs in the extracts were analyzed using liquid chromatography coupled to quadrupole-time-of-flight mass spectrometry (LC-QTOF-MS), followed by their identification and structural elucidation through a suspect and nontargeted workflow.

\section{EXPERIMENTAL SECTION}

Chemicals and Reagents. The BTR standards were purchased from Alfa Aesar and Sigma-Aldrich (Bornem, Belgium). Pooled human liver microsomes (HLMs; $n=50$, mixed gender) and pooled human liver cytosol (HLCYT, mix gender) were purchased from Tebu Bio (Boechout, Belgium) and Sigma-Aldrich, respectively. Reduced $\beta$-nicotinamide adenine dinucleotide 2 '-phosphate (NADPH; purity >95\%), uridine $5^{\prime}$-diphosphoglucuronic acid (UDPGA; purity >98\%), adenosine $3^{\prime}$-phosphate $5^{\prime}$-phosphosulfate (PAPS; purity $>96 \%$ ) lithium salt hydrate, alamethicin (neat >98\%), dimethyl sulfoxide (DMSO), theophylline (anhydrous, > 99\%) (used as internal standard, IS), phenacetin, and 4-nitrophenol were purchased from Sigma-Aldrich. Acetonitrile, methanol, ammonium acetate and formic acid were purchased from Merck kgA Chemicals (Darmstadt, Germany). Ultrapure water was obtained using an Elga LabWater water purification instrument (Saint Maurice, France).

In Vitro Biotransformation Assays. Phase I Biotransformation by CPY Enzymes. Phase I biotransformation products were generated using pooled HLMs and the $\mathrm{NADPH}$ cofactor (Figure 1). The in vitro experiment consisted 
of incubation of the xenobiotic of interest $(10 \mu \mathrm{L}$ of $0.5 \mathrm{mM}$ substrate solution) with HLM $(25 \mu \mathrm{L}$ of $20 \mathrm{mg} / \mathrm{mL}$ pooled HLM), and a buffer solution ( $955 \mu \mathrm{L} 100 \mathrm{mM}$ TRIS-HCL buffer, $\mathrm{pH} 7.5)$ in a $1.5 \mathrm{~mL}$ Eppendorf tube. The tubes are incubated at $37^{\circ} \mathrm{C}$ in a shaker bath. After $5 \mathrm{~min}$ of incubation, $10 \mu \mathrm{L}$ NADPH $(0.1 \mathrm{M}$ in buffer $)$ is added to the tubes and then the same amount is added every hour. Generation of Phase I metabolites was investigated at two different incubation times: 1 and $3 \mathrm{~h}$. The reaction is then stopped after $1 \mathrm{~h}$ and after $3 \mathrm{~h}$ by adding $250 \mu \mathrm{L}$ of ice-cold acetonitrile containing $1 \%$ formic acid $(\mathrm{v} / \mathrm{v})$ and the IS theophylline (5 $\mu \mathrm{g} / \mathrm{mL}$ ). The solution was vortexed for $30 \mathrm{~s}$ and centrifuged at $8000 \mathrm{rpm}$ for $5 \mathrm{~min}$. The supernatant was concentrated under nitrogen, transferred to a $400 \mu \mathrm{L}$ insert, and further concentrated down to $20 \mu \mathrm{L}$ of acetonitrile at $30{ }^{\circ} \mathrm{C}$, after which $180 \mu \mathrm{L}$ of ultrapure water was added. The samples were vortexed and analyzed. The samples were finally stored at -80 ${ }^{\circ} \mathrm{C}$ if further analysis was required.

Phase II Biotransformation by UGT and SULT Enzymes. UDP-glucuronosyl transferases (UGT) and sulfotransferases (SULT) enzymes are used in this study as glucuronidation and sulfation are the two main reactions occurring in phase II metabolism. Phase II metabolites were generated through glucuronidation (GLU) and sulfation (SULT) directly from the xenobiotic of interest and also from the Phase I metabolites obtained as described previously (Figure 1).

When the conjugation is performed directly on the xenobiotic of interest, $935 \mu \mathrm{L}$ (for GLU) or $965 \mu \mathrm{L}$ (for SULT) of buffer solution is prepared in an Eppendorf tube and $10 \mu \mathrm{L}$ of $0.5 \mathrm{mM}$ substrate solution is then added. For conjugation of Phase I metabolites, $3 \mathrm{~h}$ incubation as described for the Phase I experiments was performed in the first instance. Afterward, the samples were vortexed for $30 \mathrm{~s}$ and centrifuged at $8000 \mathrm{rpm}$ for $5 \mathrm{~min}$. For the GLU samples, $935 \mu \mathrm{L}$ of the supernatant was then transferred into a new Eppendorf tube with $25 \mu \mathrm{L}$ of HLM and $10 \mu \mathrm{L}$ of alamethicin $(1 \mathrm{mg} / \mathrm{mL}$ in DMSO). After $5 \mathrm{~min}$ of incubation, a spike of $10 \mu \mathrm{L}$ of UDPGA (100 $\mathrm{mM}$ in buffer) was added to the tubes to activate the reaction and then the same amount was added every hour. For the SULT samples, $965 \mu \mathrm{L}$ of the supernatant was then transferred into a new Eppendorf tube with $25 \mu \mathrm{L}$ of HLCYT $(20 \mathrm{mg} / \mathrm{mL})$ and $10 \mu \mathrm{L}$ of alamethicin $(1 \mathrm{mg} / \mathrm{mL}$ in DMSO). After $5 \mathrm{~min}$ of incubation, a spike of $10 \mu \mathrm{L}$ of PAPs (10 $\mathrm{mM}$ in buffer) was added to the tubes and then the same amount was added every hour.

After $3 \mathrm{~h}$ incubation, the reaction was stopped by adding $250 \mu \mathrm{L}$ of ice-cold acetonitrile containing $1 \%$ formic acid (v/v) and IS theophylline $(5 \mu \mathrm{g} / \mathrm{mL})$. The solution was then vortexed for $30 \mathrm{~s}$, centrifuged at $8000 \mathrm{rpm}$ for $5 \mathrm{~min}$. The supernatant was concentrated under nitrogen, transferred to a $400 \mu \mathrm{L}$ insert, and then further concentrated down to $20 \mu \mathrm{L}$ of acetonitrile at $30^{\circ} \mathrm{C}$, and $180 \mu \mathrm{L}$ of ultrapure water was added. The samples were vortexed and analyzed. The samples were finally stored at $-80{ }^{\circ} \mathrm{C}$ if further analysis was required.

LC-QTOF-MS/MS Analysis. Generated metabolites of BTRs were analyzed using LC-QTOF-MS for compound identification and elucidation. The analytical system is composed of a 1290 series LC system coupled to a 6530 QTOF-MS (Agilent Technologies) equipped with an electrospray (ESI) Jet Stream ion source. The samples were analyzed in both ESI positive (+ve) and negative (-ve) mode. For all investigated chemicals except $1 \mathrm{H}-\mathrm{BTR}$, the chromatographic separation of the metabolites was achieved using a biphenyl column (Phenomenex, $100 \times 2.1 \mathrm{~mm}, 2.6 \mu \mathrm{m}$ ). The mobile phase composition for ESI negative mode was $5 \mathrm{mM}$ ammonium acetate in both water (A) and acetonitrile (B) and for ESI positive mode $1 \%$ formic acid in both water (A) and acetonitrile (B). For the analysis, the gradient of elution was $5 \%$ B during 2 min, linear gradient from 5 to $57 \%$ B from 2 to $28 \mathrm{~min}$, linear gradient from 57 to $95 \%$ B from 28 to 28.1 min, isocratic conditions at $95 \%$ B from 28.1 to $32.0 \mathrm{~min}$, and finally isocratic conditions at 5\% B from 32.1 to $36.0 \mathrm{~min}$. The flow was $0.3 \mathrm{~mL} / \mathrm{min}$, the column oven temperature was set at $40{ }^{\circ} \mathrm{C}$, and the injection volume was $8 \mu \mathrm{L}$.

For $1 \mathrm{H}-\mathrm{BTR}$, the separation was performed using a T3 column. The mobile phase composition for ESI negative mode was $5 \mathrm{mM}$ ammonium acetate in both water (A) and acetonitrile (B) and for ESI positive mode 1\% formic acid in both water (A) and acetonitrile (B). For the analysis in positive ionization mode, the gradient of elution was $5 \% \mathrm{~B}$ during 2 min, linear gradient from 5 to $41 \%$ B from 2 to 20 min, linear gradient from 41 to $95 \%$ B from 20 to $21.5 \mathrm{~min}$, isocratic conditions at $95 \%$ B from 21.5 to $26.0 \mathrm{~min}$, and finally isocratic conditions at $5 \%$ B from 26.1 to $30.0 \mathrm{~min}$. The flow was 0.2 $\mathrm{mL} / \mathrm{min}$, the column oven temperature was set at $40{ }^{\circ} \mathrm{C}$, and the injection volume was $8 \mu \mathrm{L}$.

The QTOF-MS instrument was operated in the $2 \mathrm{GHz}$ (extended dynamic range) mode, providing a full width at half maximum (FWHM) resolution of approximately 5400 at $\mathrm{m} / z$ 112.9856 and 11,000 at $m / z 1033.9881$. To ensure high mass accuracy during analysis, a calibration solution (Agilent Technologies) with reference masses (ESI +ve: $\mathrm{m} / z$ 121.0508 and 922.0098; ESI -ve: $m / z \quad 112.9855$ and 980.0153) was continuously infused in the QTOF-MS system. The QTOF-MS was set to scan from 50 to $1000 \mathrm{~m} / z$ at a rate of 2.5 spectra/s for MS and 6.67 spectra/s for MS/MS, using a data-dependent acquisition mode (auto-MS/MS) with three collision energy values $(10,20$, and $40 \mathrm{~V})$. A maximum of three precursor ions per MS cycle was set with a minimal intensity of 5000 counts. To avoid repetitive MS/MS spectra acquisition of the same precursor ion, an active exclusion function was assigned to exclude the precursor ions after every two spectra and release it after $0.1 \mathrm{~min}$. When $\mathrm{MS} / \mathrm{MS}$ spectra were missing, additional injections in targeted MS/MS mode with selected precursor ions were executed to obtain fragmentation spectra for some metabolites. The following MS parameters were used: gas temperature $300{ }^{\circ} \mathrm{C}$, gas flow $8 \mathrm{~L} / \mathrm{min}$, nebulizer pressure $25 \mathrm{psi}$, sheath gas temperature $350{ }^{\circ} \mathrm{C}$, sheath gas flow $11 \mathrm{~L} / \mathrm{min}$. Nozzle, capillary, fragmentor, and skimmer voltages were set to $500,3500,120$, and $65 \mathrm{~V}$, respectively.

Suspected Screening, Nontargeted Screening, and Data Processing. The Meteor Nexus software (Lhasa limited, U.K.) was used to predict potential BTR metabolites that can be produced by specific human liver enzymes. A list of potential metabolites for suspect screening was created for further data processing (SI.1). The prediction parameters used were as follows: all redox and nonredox metabolism with the biotransformation involving CYP, SULT, an UGT enzymes, the maximum number of metabolic steps was set at three, and the maximum number of predicted metabolites was limited at 200. The list of metabolites included all the degrees of likelihood including probable, plausible, and equivocal metabolites. Meteor Nexus predicted a list of 29, 26, and 13 metabolites for H-BTR, 4-TTR, and 5-Cl-BTR, respectively. 
An open-source software MZmine 2.7 (http://mzmine. github.io/) was used to perform a nontarget screening of potential biotransformation products. ${ }^{18}$ The raw data files acquired were converted to $\mathrm{mzXML}$ format for the screening process. Various algorithms were applied to detect and differentiate MS features between different sets of samples (treated samples vs controls). Briefly, $m / z$ features were revealed by the centroid algorithm followed by a chromatogram-building step. The obtained chromatograms were deconvoluted using the noise amplitude algorithm, and further deisotoped for the lowest $\mathrm{m} / z$ as the main isotope. During the deisotope step, chromatographic peaks were also selected with the peak width between 0.05 and $1 \mathrm{~min}$. Then, peak alignments across samples were performed using the Random Sample Consensus (RANSAC) algorithm. The Same RT and $\mathrm{m} / \mathrm{z}$ range gap filler algorithms were used to reiteratively extract any possibly missing peaks. The obtained $m / z$ features were analyzed and visualized through a volcano plot (GraphPad Prism Software, v 7.04), where for each obtained $m / z$ ion, the Student $t$ test's $p$-value was plotted against the fold-change in the intensity between treated and control samples. Selection of $m / z$ ions for further processing was based on a fold-change $>10$ and a $p$-value $<0.05$.

Identification of Biotransformation Products. The $\mathrm{m} /$ $z$ features obtained from the suspected and nontarget screening approaches were extracted in the raw data files with different algorithms, including the "Find by Formula", "Find by AutoMS/MS", and "Generate Formulas", in the MassHunter Qualitative software (Agilent Technologies). The main criteria for the identification ${ }^{19}$ of metabolites were based on (a) the accurate mass measurement (maximum mass error $\pm 10 \mathrm{ppm}$ for precursor ions and $\pm 20 \mathrm{ppm}$ for product ions), (b) an isotope abundance score of at least 70 in a matching between the measured and predicted isotope patterns, (c) ring and double bonds (RDB) factor agreed with the postulated structure, (d) an absence of the identified biotransformation products in the related negative control samples, and (e) structural elucidations of precursors agreed with MS/MS spectrum interpretation. Structures of the proposed metabolites were drawn using the software ChemBioDraw Ultra 14.0 (PerkinElmer Inc.).

Quality Assurance and Control (QA/QC). Different negative control samples, without the substrate, enzyme, or cofactor, were included for each experimental setup, to avoid false positive identifications of bioTPs. Solvent blank samples (reconstitution solution) were also included during the analysis to check any instrumental contamination. Phenacetin and 4nitrophenol were used as the substrate for the positive control samples in Phase I and Phase II in vitro experiments, respectively. The well-known metabolites of these positive control compounds were monitored during data processing. Duplicate treated in vitro samples were prepared. Theophylline was used as the IS to compensate instrumental variations during analysis (e.g., injection volume) and can be ionized in both +ve and -ve ESI. The presence of false positive peaks due to in-source fragmentation was also investigated by comparing retention times.

All identified bioTPs were not found in the negative control samples and instrumental blank samples. For the positive control, the Phase I experiment was evaluated through monitoring the biotransformation products of phenacetin, $\mathrm{N}$ (4-hydroxyphenyl)-acetamide (oxidative dealkylation) and $\mathrm{N}$ (4-ethoxy-2-hydroxyphenyl)-acetamide (hydroxylation), while the Phase II experiment was based on the conjugated biotransformation products of 4-nitrophenol: 4-nitrophenol glucuronide and 4-nitrophenol sulfate (see chromatograms, MS and MS/MS spectra in SI.2). The obtained positive control data suggested the adequate performance of our in vitro experimental assays. The changes in the response of theophylline (IS) across all samples during the analysis was 5-8\% (relative standard deviation), indicating an acceptable experimental and instrumental variation.

\section{RESULTS AND DISCUSSION}

Identification of bioTPs. Two complementary workflows were employed to identify the potential bioTPs of the target BTRs in both +ve and -ve ESI modes. A summary of all the identified bioTPs is presented in Supporting Information. The number assigned to the bioTPs is based on the retention time (early to later elusion) in +ve ESI followed by -ve ESI, with letters to differentiate isomers. Briefly, in vitro incubation with HLMs has resulted in the formation of two Phase I and eight Phase II bioTPs for H-BTR (Table SI-1), five Phase I and nine Phase II bioTPs for 4-TTR (Table SI-2), and four Phase I and ten Phase II bioTPs for 5-Cl-BTR (Table SI-3).

Phase I bioTPs of 1H-BTR. With CYP enzymes, two hydroxylated $1 \mathrm{H}-\mathrm{BTR}$ bioTPs (M4-A and - $\mathrm{B} ; \mathrm{C}_{6} \mathrm{H}_{5} \mathrm{~N}_{3} \mathrm{O}$ ) were identified as $[\mathrm{M}-\mathrm{H}]^{-}\left(\left[\mathrm{C}_{6} \mathrm{H}_{4} \mathrm{~N}_{3} \mathrm{O}\right]^{-}, m / z\right.$ 134.0360, $\Delta m=$ $-10.7 \mathrm{ppm})$ eluting at 6.34 and $7.23 \mathrm{~min}$, which were 3.64 and $2.75 \mathrm{~min}$ earlier than $1 \mathrm{H}-\mathrm{BTR}$ (9.98 $\mathrm{min}$ ), respectively (Table SI-1). The response of M4-A and -B represented approximately $23 \%$ and $77 \%$ of the total response of Phase I bioTPs, respectively. The main common fragment ions obtained were $m / z 78.0381\left(\left[\mathrm{C}_{5} \mathrm{H}_{4} \mathrm{~N}\right]^{-}\right)$and $m / z 106.0302\left(\left[\mathrm{C}_{6} \mathrm{H}_{4} \mathrm{NO}\right]^{-}\right)$. The isotopic pattern and double bond equivalent (DBE) were in accordance with the proposed structure. However, the exact position of the hydroxylation for the two isomers could not be elucidated with the acquired MS/MS data.

Phase // bioTPs of $1 \mathrm{H}-\mathrm{BTR}$. Further biotransformation of M4 with UGT enzymes was observed, resulting in glucuronidated hydroxy-BTR (M1). As more polar, M1 was detected at $2.33 \mathrm{~min}$, earlier than M4. M1 was identified as $[\mathrm{M}-\mathrm{H}]^{-}$ $\left(\left[\mathrm{C}_{12} \mathrm{H}_{12} \mathrm{~N}_{3} \mathrm{O}_{7}\right]^{-}, m / z 310.0691, \Delta m=8.2 \mathrm{ppm}\right)$ (Table SI- 1 ). Due to overly low intensity, no MS/MS data have been picked up for M1. Yet, its mass difference of $176.03 \mathrm{amu}$ from M4 highly suggests a loss of the glucuronide moiety $\left[\mathrm{C}_{6} \mathrm{H}_{8} \mathrm{O}_{6}\right]^{-}$, and also its increased DBE by 2 units compared to M4 tends to propose the presence of glucuronic acid (DBE 2) in M1. In this light, glucuronidation could take place within the triazole ring or the phenol of M4. Again, because of low intensity for M1, chromatographic peaks for the potential isomers could not be revealed.

Similarly, after incubating the Phase I reaction mixture containing M4 with SULT enzymes, four sulfated hydroxy-HBTR bioTPs (M3-A, -B, -C, and -D) were detected as [M$\mathrm{H}]^{-}\left(\left[\mathrm{C}_{6} \mathrm{H}_{4} \mathrm{~N}_{3} \mathrm{O}_{4} \mathrm{~S}\right]^{-}, m / z 213.9928, \Delta m=-10.3 \mathrm{ppm}\right)$ at $3.56,4.23,4.80$, and $5.50 \mathrm{~min}$, respectively (Table SI-1). The retention time of these four isomers indicates that they are more polar than M4. The main fragment ions obtained were $m / z 134.0376\left(\left[\mathrm{C}_{6} \mathrm{H}_{4} \mathrm{~N}_{3} \mathrm{O}\right]^{-}\right)$and $m / z \quad 106.0311$ $\left(\left[\mathrm{C}_{6} \mathrm{H}_{4} \mathrm{NO}\right]^{-}\right)$. The mass difference between $\mathrm{M} 3$ and $\left[\mathrm{C}_{6} \mathrm{H}_{4} \mathrm{~N}_{3} \mathrm{O}\right]^{-}$(i.e., M4) was $79.9568 \mathrm{amu}$, corresponding to a loss of the sulfo moiety $\left[\mathrm{SO}_{3}\right]^{-}$, while another fragment $\left(\left[\mathrm{C}_{6} \mathrm{H}_{4} \mathrm{NO}\right]^{-}\right)$was also found for M4. The conjugation could sulfate within the triazole ring or the phenol of M4, suggesting four isomers for M3. 
When exposing 1H-BTR directly to UGT and SULT enzymes, glucuronidated and sulfated bioTPs were observed (Table SI-1). Two glucuronidated bioTPs of BTR (M2-A and $-\mathrm{B})$, eluted at 2.51 and $3.71 \mathrm{~min}$, were identified as $[\mathrm{M}-\mathrm{H}]^{-}$ $\left(\left[\mathrm{C}_{12} \mathrm{H}_{12} \mathrm{~N}_{3} \mathrm{O}_{6}\right]^{-}, m / z\right.$ 294.0732, $\left.\Delta m=-7.88 \mathrm{ppm}\right)$. These two bioTPs were also found in the further incubation of Phase I reaction mixture with UGT enzymes. The MS/MS spectra with $\mathrm{m} / z 118.0408\left(\left[\mathrm{C}_{6} \mathrm{H}_{4} \mathrm{~N}_{3}\right]^{-}\right.$corresponding to BTR $)$and $m / z 175.0243\left(\left[\mathrm{C}_{6} \mathrm{H}_{8} \mathrm{O}_{6}\right]^{-}\right.$corresponding to the glucuronide moiety) and DBE 8 ( 2 units more than BTR from the addition of glucuronic acid) indicated the glucuronidation of BTR. As glucuronidation requires an electron-rich nucleophilic heteroatom, the conjugation is more preferable to occur within the triazole ring. Glucuronidated isomers are likely due to the $\mathrm{N}$ substitution on position 1 (glucuronidated-1H-BTR) and position 2 (glucuronidated-2H-BTR) of BTR, which is tautomeric.

Sulfated H-BTR (M5) was identified as [M$\mathrm{H}]^{-}\left(\left[\mathrm{C}_{6} \mathrm{H}_{4} \mathrm{~N}_{3} \mathrm{O}_{3} \mathrm{~S}\right]^{-}, m / z 197.9979, \Delta m=-5 \mathrm{ppm}\right)$ at 9.17 min. It was also observed in the further incubation of Phase I reaction mixture with SULT enzymes. The fragment ion of $m$ / $z 118.0392\left[\mathrm{C}_{6} \mathrm{H}_{4} \mathrm{~N}_{3}\right]^{-}(\Delta m=-3.6 \mathrm{ppm})$ corresponded to BTR itself. The mass difference of $79.9568 \mathrm{amu}$ between M5 and $\left[\mathrm{C}_{6} \mathrm{H}_{4} \mathrm{~N}_{3}\right]^{-}$indicated a loss of the sulfo moiety $\left[\mathrm{SO}_{3}\right]^{-}$. As sulfation favors hydroxyl or amine groups, the related conjugation for M5 is likely to be within the triazole ring. Only one sulfated bioTP observed, compared to two glucuronidated isomers (M2-A and -B), suggests that another sulfated isomer may be below the instrumental detection limit, or the sulfated conjugation by SULT enzymes could be stereospecific in only one position of the triazole ring.

Biotransformation Patterns of 1H-BTR. The transformation pathway of $1 \mathrm{H}-\mathrm{BTR}$ was mainly composed of hydroxylated and conjugated bioTPs (Figure 2A). A continuous and significant increase in the amount of M4-A and -B (hydroxylated bioTP isomers) was observed over incubation times (see Figure SI-3), with a factor of about 4.1 $(1 \mathrm{~h})$ and $3.6(3 \mathrm{~h})$ between them. These two bioTPs were not detected in the samples of the $3 \mathrm{~h}$ Phase II experiment for GLU and SULT conjugation (Figure SI-4), suggesting a substantial biotransformation into glucuronidated and sulfated conjugates. Based on the peak area (Figure SI-4), the average MS signal area of sulfated hydroxyl-BTR bioTPs (M3) was the greatest and about 30 times higher than that of the glucuronide conjugates (M1). The lack of hydroxylated 1H-BTR after CYP/GLU and CYP/SULT mediated reaction suggests that the hydroxylated bioTPs are fully transformed to Phase II conjugate. This, however, is only a brief comparison that would depend on the biotransformation rate between the two different conjugation reactions and on the instrumental sensitivity of individual compound.

Our results of two hydroxylated isomers (M4) are consistent with those of another study, which reported the formation of 4-OH- and 5-OH-BTR after a $1 \mathrm{~h}$ incubation of $1 \mathrm{H}-\mathrm{BTR}$ with rat liver microsomes, and 5-OH-BTR was 4-5 times more abundant than another isomer (Health Council of The Netherlands, 2000). Despite there being very little information about the metabolism of $1 \mathrm{H}-\mathrm{BTR}$ in humans or mammals, our findings reveal that human in vitro biotransformation of $1 \mathrm{H}$ BTR was not limited to Phase I levels, but promoted further to glucuronidation and sulfation as continuous detoxification in vitro for more polar bioTPs (glu-hydroxy-BTR (M1), the earliest eluted bioTP). Also, glucuronidation resulted in more

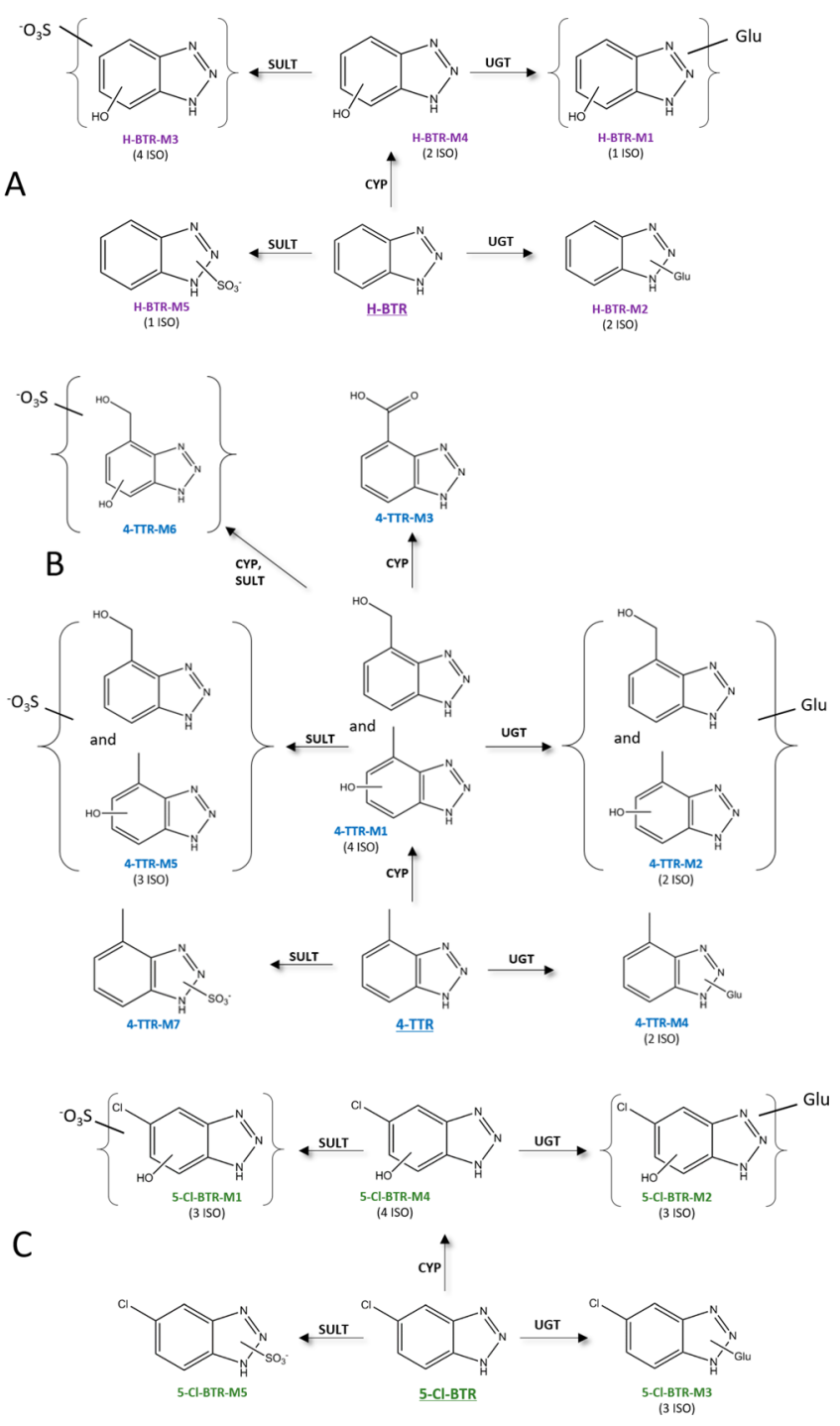

Figure 2. Proposed in vitro metabolic pathway for H-BTR (A), 4TTR (B), and 5-Cl-BTR (C) based on the bioTPs identified in this study.

polar bioTPs than sulfation (Table SI-1). It appears worthy to assess and monitor these Phase II bioTPs of BTR, besides BTR itself, in future in vivo studies.

Phase I bioTPs of 4-TTR. Four CYP-mediated hydroxy-4TTR bioTPs (M1-A, -B, -C, and -D) were identified as [M $+\mathrm{H}]^{+}\left(\left[\mathrm{C}_{7} \mathrm{H}_{8} \mathrm{~N}_{3} \mathrm{O}\right]^{+}, m / z 150.0662, \Delta m=-0.30 \mathrm{ppm}\right)$ at 3.2, $4.1,5.5$, and $6.7 \mathrm{~min}$, respectively (Table SI-2). The two most abundant isomers were M1-A and M1-C, representing 40\% and $48 \%$ of the total response of Phase I bioTPs, respectively. The mass difference between M1 and 4-TTR was 15.9949 $\mathrm{amu}$, indicating an oxidation biotransformation (oxygen addition to $\mathrm{M} 1$ ). All these isomers showed common fragment ions in positive $\left(77.0386\left[\mathrm{C}_{6} \mathrm{H}_{5}\right]^{+}\right)$and negative mode $\left(118.0427\left[\mathrm{C}_{6} \mathrm{H}_{4} \mathrm{~N}_{3}\right]^{-}, 90.0369\left[\mathrm{C}_{6} \mathrm{H}_{4} \mathrm{~N}\right]^{-}, 105.0232\right.$ $\left.\left[\mathrm{C}_{6} \mathrm{H}_{3} \mathrm{NO}\right]^{-}\right)$, which were also found for 4-TTR. The hydroxylation for these four isomers could be on the methyl group and the benzene ring. Based on the acquired MS/MS data, the exact position of the hydroxyl group could not be determined. However, the more favorable reaction sites for hydroxylation would be in position 5 of the aromatic cycle and on the methyl group next to the aromatic group. 
Biotransformation of 4-TTR was also catalyzed by CYP enzymes to carboxylic-TTR (M3), eluted at $5.64 \mathrm{~min}$ as $[\mathrm{M}+$ $\mathrm{H}]^{+}\left(\left[\mathrm{C}_{7} \mathrm{H}_{6} \mathrm{~N}_{3} \mathrm{O}_{2}\right]^{+}, m / z 164.0455, \Delta m=-4.39 \mathrm{ppm}\right)$. Three most abundant fragment ions, $m / z 146.0338\left(\left[\mathrm{C}_{7} \mathrm{H}_{4} \mathrm{~N}_{3} \mathrm{O}\right]^{+}\right.$, after a loss of $\left.\mathrm{H}_{2} \mathrm{O}\right), 118.0265\left(\left[\mathrm{C}_{6} \mathrm{H}_{4} \mathrm{~N}_{3}\right]^{+}\right.$, i.e., BTR $)$, and $45.0324\left(\left[\mathrm{CHO}_{2}\right]^{+}\right.$, carboxylate $)$, suggested the oxidation of the methyl group on the benzo ring. Also, the carboxylate moiety can be elucidated by DBE of 7 for M3 compared to 4TTR (DBE 6).

Phase // bioTPs of 4-TTR. In the presence of UGT enzymes, glucuronidated hydroxyl-bioTPs (M2-A and -B) were identified at 4.44 and $4.78 \mathrm{~min}$ as $[\mathrm{M}+\mathrm{H}]^{+}\left(\left[\mathrm{C}_{13} \mathrm{H}_{16} \mathrm{~N}_{3} \mathrm{O}_{7}\right]^{+}, \mathrm{m} / z\right.$ 326.0983, $\Delta m=3 \mathrm{ppm})$. The chromatographic peak at 4.78 min (M2-A) showed slightly higher intensity. A loss of the glucuronide moiety $\left[\mathrm{C}_{6} \mathrm{H}_{8} \mathrm{O}_{6}\right]$ from $\left[\mathrm{C}_{13} \mathrm{H}_{16} \mathrm{~N}_{3} \mathrm{O}_{7}\right]^{+}$(M2) resulted in the main fragment $m / z 150.0665\left[\mathrm{C}_{7} \mathrm{H}_{8} \mathrm{~N}_{3} \mathrm{O}\right]^{+}$(i.e., hydroxy-TTR ions). Also, the DBE value of 8 was in agreement with the proposed structure. The glucuronidation reaction could take place at the hydroxyl group of the primary aliphatic alcohol and/or at the phenol group of M1, suggesting two conjugated isomer bioTPs.

Similarly, three sulfated hydroxy-TTR bioTPs (M5-A, -B, and $-\mathrm{C})$ were detected as $[\mathrm{M}-\mathrm{H}]^{-}\left(\left[\mathrm{C}_{7} \mathrm{H}_{6} \mathrm{~N}_{3} \mathrm{O}_{4} \mathrm{~S}^{-}\right]^{-}, \mathrm{m} / z\right.$ 228.0085, $\Delta m=-6.98 \mathrm{ppm})$ at $1.4,1.7$, and $2.7 \mathrm{~min}$. The most abundant isomer M5-C contributes to $94 \%$ of the total response of the three isomers. The fragment ions at $\mathrm{m} / z$ $148.0535\left(\left[\mathrm{C}_{7} \mathrm{H}_{6} \mathrm{~N}_{3} \mathrm{O}\right]^{-}\right), 120.0461\left(\left[\mathrm{C}_{7} \mathrm{H}_{6} \mathrm{NO}\right]^{-}\right)$, and $80.9674\left(\left[\mathrm{SO}_{3} \mathrm{H}\right]^{-}\right)$suggested conjugation of the hydroxyTTR (M1) by SULT enzymes. This could occur at the hydroxyl group of the primary aliphatic alcohol and phenol or on the triazole ring to result in different isomers.

Moreover, sulfation of dihydroxyl-4-TTR to conjugated hydroxyl-4-TTR (M6-A) was detected at $2.1 \mathrm{~min}$ as $[\mathrm{M}-\mathrm{H}]^{-}$ $\left(\left[\mathrm{C}_{7} \mathrm{H}_{6} \mathrm{~N}_{3} \mathrm{O}_{5} \mathrm{~S}\right]^{-}, m / z\right.$ 244.0034, $\left.\Delta m=-12.8 \mathrm{ppm}\right)$. The fragment ions presenting the highest relative abundance are $m$ / $z 136.0419$ (100\%), 164.0486 (80\%), 96.9619 (46\%), and $79.9601(36 \%)$ corresponding to $\left[\mathrm{C}_{7} \mathrm{H}_{6} \mathrm{~N}_{3} \mathrm{O}_{2}\right]^{-},\left[\mathrm{C}_{7} \mathrm{H}_{6} \mathrm{NO}_{2}\right]^{-}$, $\left[\mathrm{HSO}_{4}\right]^{-}$, and $\left[\mathrm{SO}_{3}\right]^{-}$, respectively. The mass loss of 79.96 amu between $[\mathrm{M}-\mathrm{H}]^{-}$and $\left[\mathrm{C}_{7} \mathrm{H}_{6} \mathrm{~N}_{3} \mathrm{O}_{2}\right]^{-}$suggested a loss of the $\left[\mathrm{SO}_{3}\right]$ moiety. The presence of the fragment $\left[\mathrm{HSO}_{4}\right]^{-}$ implied the sulfation of one hydroxyl group. The DBE of 6 and isotopic pattern also confirmed the proposed structure. While sulfated hydroxyl-4-TTR was tentatively identified, no dihydroxyl-TTR metabolites were found in Phase I and Phase II experiments. This could be due to the instrumental detection limit to these compounds.

When incubating 4-TTR with UGT and SULT enzymes, respectively, glucuronidated (M4-A and B) and sulfated (M7) 4-TTR bioTPs were identified. Two glucuronidated isomers were found as $[\mathrm{M}+\mathrm{H}]^{+}\left(\left[\mathrm{C}_{13} \mathrm{H}_{16} \mathrm{~N}_{3} \mathrm{O}_{6}\right]^{+}, m / z 310.1034, \Delta m\right.$ $=-3.12 \mathrm{ppm})$ at 6.64 and $7.97 \mathrm{~min}$. A mass difference of $176.03153 \mathrm{amu}$ between $[\mathrm{M}+\mathrm{H}]^{+}$and the most abundant fragment ion, $m / z 134.0701\left[\mathrm{C}_{7} \mathrm{H}_{8} \mathrm{~N}_{3}\right]^{+}$, suggested a loss of the glucuronide moiety $\left[\mathrm{C}_{6} \mathrm{H}_{8} \mathrm{O}_{6}\right]$. Increased $\mathrm{DBE}$ value to 8 also indicated the conjugation with glucuronic acid. This occurred very likely at the $1 \mathrm{H}$ or $2 \mathrm{H}$ of amine in the triazole ring for the two isomers.

Similarly, 4-TTR was directly biotransformed by SULT enzymes, resulting in sulfated-TTR (M7). It was identified as $[\mathrm{M}-\mathrm{H}]^{-}\left(\left[\mathrm{C}_{7} \mathrm{H}_{6} \mathrm{~N}_{3} \mathrm{O}_{3} \mathrm{~S}\right]^{-}, m / z 212.0135, \Delta m=0.15 \mathrm{ppm}\right)$ at $6.60 \mathrm{~min}$. The mass difference between $[\mathrm{M}-\mathrm{H}]^{-}$and the main fragment ion $\left[\mathrm{C}_{7} \mathrm{H}_{6} \mathrm{~N}_{3}\right]^{-}$is $79.9568 \mathrm{amu}$, corresponding to a loss of the $\left[\mathrm{SO}_{3}\right]$ moiety.
Biotransformation Patterns of 4-TTR. CYP-mediated hydroxylation and oxidation to carboxylated bioTPs followed by Phase II conjugates were noticed as the major biotransformation pattern of 4-TTR (Figure 2B). When plotting the ratio response of the metabolite area normalized by the internal standard area versus the incubation time at 1 and $3 \mathrm{~h}$ (Figure SI-5), a slight increase is observed for M1 and M3 metabolites. M1 isomers and M3 were still detected after phase II experiments, but presented a significantly lower response suggesting their transformation into SULT and GLU conjugates (Figure SI-6). In terms of MS peak area (Figure SI6 ), the sulfonate hydroxy metabolites were the most abundant with an area around 7 times higher than the glucuronidation. However, these observations can be linked to different biotransformation rates between the hydroxy metabolites and their conjugates and to their respective sensitivity in LC-MS analysis. Similar to $1 \mathrm{H}-\mathrm{BTR}$, in vitro human biotransformation of 4-TTR was not only mediated by CYP enzymes, but also by UGT and SULT enzymes to result in more hydrophilic bioTPs in vitro.

Phase I bioTPs of 5-Cl-BTR. With CYP enzymes, four hydroxy-5-Cl-BTR bioTPs (M4-A, -B, -C, and -D) were identified as $[\mathrm{M}-\mathrm{H}]^{-}\left(\left[\mathrm{C}_{6} \mathrm{H}_{3} \mathrm{ClN}_{3} \mathrm{O}\right]^{-}, m / z\right.$ 167.9970, $\Delta_{\mathrm{m}}=$ $-8.76 \mathrm{ppm}$ ) eluted at $3.0,4.7,5.1$, and $6.5 \mathrm{~min}$, respectively. The two most abundant isomers were M4-A and M4-C, presenting $28 \%$ and $53 \%$ of the total response of Phase I bioTPs, respectively. The more abundant fragment ions are $132.0227\left(\left[\mathrm{C}_{6} \mathrm{H}_{2} \mathrm{~N}_{3} \mathrm{O}\right]^{-}\right)$and $152.0009\left(\left[\mathrm{C}_{6} \mathrm{H}_{3} \mathrm{ClN}_{3}\right]^{-}\right)$. The hydroxylation could take place at the benzo ring and triazole ring. The abundance isotopic profile matches at $98 \%$ with the proposed formula.

Phase II bioTPs of 5-Cl-BTR. Glucuronidation of the hydroxy-5-Cl-BTR bioTPs (M1-A, -B, and -C) were identified at $1.1,2.6$, and $3.5 \mathrm{~min}$ as $[\mathrm{M}-\mathrm{H}]^{-}\left(\left[\mathrm{C}_{12} \mathrm{H}_{11} \mathrm{ClN}_{3} \mathrm{O}_{7}\right]^{-}, \mathrm{m} / z\right.$ $344.0291, \Delta m=9.2)$. They represented $28 \%, 47 \%$, and $25 \%$ of the total intensity, respectively. Due to low intensity, MS/MS spectra of M1 were impossible to acquire even using target MS/MS mode. However, the low $\Delta m$, retention time prediction, DBE, and the isotopic pattern are in line with the proposed chemical formula. Acquisition of MS/MS data would be necessary to add more confidence in the proposed structure.

Conjugation of hydroxy-5-Cl-BTR with SULT enzymes for Phase II bioTPs (M2-A, -B, and -C) were detected at 1.9, 2.8, and $3.5 \mathrm{~min}$ as $[\mathrm{M}-\mathrm{H}]^{-}\left(\left[\mathrm{C}_{6} \mathrm{H}_{3} \mathrm{ClN}_{3} \mathrm{O}_{4} \mathrm{~S}\right]^{-}, \mathrm{m} / z 247.9538\right.$ ppm, $\Delta m=-1.38 \mathrm{ppm})$ and represented $38 \%, 44 \%$, and $18 \%$ of the total intensity, respectively. The main fragment ion, $\mathrm{m} / \mathrm{z}$ $167.9987(100 \%)$, was common to all isomers and corresponded to $\left[\mathrm{C}_{6} \mathrm{H}_{3} \mathrm{ClN}_{3} \mathrm{O}\right]^{-}$(i.e., hydroxylated-5-Cl-BTR bioTPs (M4)). The mass loss between this fragment ion and $[\mathrm{M}-\mathrm{H}]^{-}$of M2 isomers was $79.96 \mathrm{amu}$, suggesting a loss of $\left[\mathrm{SO}_{3}\right]$, probably from the phenol moiety or also amines of the triazole ring. The DBE of 6 and isotopic pattern are cohesive with the proposed molecular formula.

Direct conjugation of 5-Cl-BTR with UGT and SULT enzymes was also detected. Three glucuronidated 5-Cl-BTR bioTPs (M3-A, -B, and $-\mathrm{C}$ ) were found as $[\mathrm{M}-\mathrm{H}]^{-}$ $\left(\left[\mathrm{C}_{12} \mathrm{H}_{11} \mathrm{ClN}_{3} \mathrm{O}_{6}\right]^{-}, m / z\right.$ 328.0342, $\left.\Delta m=-3.9 \mathrm{ppm}\right)$ at 2.3, 2.7 , and $4.1 \mathrm{~min}$, and represent $30 \%, 23 \%$, and $47 \%$, respectively, of the total MS intensity. For all isomers, the main fragment ion was $m / z 152.0050\left(\left[\mathrm{C}_{6} \mathrm{H}_{3} \mathrm{ClN}_{3}\right]^{-}\right)$which is 5-Cl-BTR. The mass difference between the molecular ion and $\left[\mathrm{C}_{6} \mathrm{H}_{3} \mathrm{ClN}_{3}\right]^{-}$was $176.03 \mathrm{amu}$, referring to a loss of the glucuronide moiety. The well-fitting isotopic profile and DBE 
Table 1. Proposed Biomarkers to Be Considered in Further Biomonitoring Studies

\begin{tabular}{|c|c|c|c|}
\hline Parent chemical & $\begin{array}{l}\text { chemicals targeted in } \\
\text { the literature }\end{array}$ & bioTPs identified in this study & $\begin{array}{l}\text { bioTPs to be considered after } \\
\text { enzymatic deconjugation }\end{array}$ \\
\hline $\begin{array}{l}\mathrm{H}-\mathrm{BTR} \\
\left(\mathrm{C}_{6} \mathrm{H}_{5} \mathrm{~N}_{3}\right)\end{array}$ & $\mathrm{C}_{6} \mathrm{H}_{5} \mathrm{~N}_{3}, \mathrm{C}_{6} \mathrm{H}_{5} \mathrm{~N}_{3} \mathrm{O}$ & $\mathrm{C}_{6} \mathrm{H}_{5} \mathrm{~N}_{3} \mathrm{O}, \mathrm{C}_{6} \mathrm{H}_{5} \mathrm{~N}_{3} \mathrm{O}_{4} \mathrm{~S}, \mathrm{C}_{6} \mathrm{H}_{5} \mathrm{~N}_{3} \mathrm{O}_{3} \mathrm{~S}, \mathrm{C}_{12} \mathrm{H}_{13} \mathrm{~N}_{3} \mathrm{O}_{7}, \mathrm{C}_{12} \mathrm{H}_{13} \mathrm{~N}_{3} \mathrm{O}_{6}$ & ${ }^{a} \mathrm{C}_{6} \mathrm{H}_{5} \mathrm{~N}_{3} \mathrm{O}$ \\
\hline $\begin{array}{l}5-\mathrm{Cl}-\mathrm{BTR} \\
\left(\mathrm{C}_{6} \mathrm{H}_{4} \mathrm{ClN}_{3}\right)\end{array}$ & $\mathrm{C}_{6} \mathrm{H}_{4} \mathrm{ClN}_{3}$ & $\mathrm{C}_{6} \mathrm{H}_{4} \mathrm{ClN}_{3} \mathrm{O}, \mathrm{C}_{6} \mathrm{H}_{4} \mathrm{ClN}_{3} \mathrm{O}_{4} \mathrm{~S}, \mathrm{C}_{6} \mathrm{H}_{4} \mathrm{ClN}_{3} \mathrm{O}_{3} \mathrm{~S}, \mathrm{C}_{12} \mathrm{H}_{12} \mathrm{ClN}_{3} \mathrm{O}_{7}, \mathrm{C}_{12} \mathrm{H}_{12} \mathrm{ClN}_{3} \mathrm{O}_{6}$ & ${ }^{a} \mathrm{C}_{6} \mathrm{H}_{4} \mathrm{ClN}_{3} \mathrm{O}$ \\
\hline $\begin{array}{l}\text { 4-TTR } \\
\qquad\left(\mathrm{C}_{7} \mathrm{H}_{7} \mathrm{~N}_{3}\right)\end{array}$ & $\mathrm{C}_{7} \mathrm{H}_{7} \mathrm{~N}_{3}$ & $\begin{array}{l}\mathrm{C}_{7} \mathrm{H}_{7} \mathrm{~N}_{3} \mathrm{O}, \mathrm{C}_{7} \mathrm{H}_{5} \mathrm{~N}_{3} \mathrm{O}_{2}, \mathrm{C}_{7} \mathrm{H}_{7} \mathrm{~N}_{3} \mathrm{O}_{3} \mathrm{~S}, \mathrm{C}_{7} \mathrm{H}_{7} \mathrm{~N}_{3} \mathrm{O}_{4} \mathrm{~S}, \mathrm{C}_{7} \mathrm{H}_{7} \mathrm{~N}_{3} \mathrm{O}_{5} \mathrm{~S}, \mathrm{C}_{13} \mathrm{H}_{15} \mathrm{~N}_{3} \mathrm{O}_{6} \\
\mathrm{C}_{13} \mathrm{H}_{15} \mathrm{~N}_{3} \mathrm{O}_{7}\end{array}$ & ${ }^{a} \mathrm{C}_{7} \mathrm{H}_{7} \mathrm{~N}_{3} \mathrm{O}, \mathrm{C}_{7} \mathrm{H}_{5} \mathrm{~N}_{3} \mathrm{O}_{2}, \mathrm{C}_{7} \mathrm{H}_{7} \mathrm{~N}_{3} \mathrm{O}_{2}$ \\
\hline $\begin{array}{l}\text { 5-TTR } \\
\left(\mathrm{C}_{7} \mathrm{H}_{7} \mathrm{~N}_{3}\right)\end{array}$ & $\mathrm{C}_{7} \mathrm{H}_{7} \mathrm{~N}_{3}$ & $\begin{array}{l}\mathrm{C}_{7} \mathrm{H}_{7} \mathrm{~N}_{3} \mathrm{O}, \mathrm{C}_{7} \mathrm{H}_{5} \mathrm{~N}_{3} \mathrm{O}_{2}, \mathrm{C}_{7} \mathrm{H}_{7} \mathrm{~N}_{3} \mathrm{O}_{3} \mathrm{~S}, \mathrm{C}_{7} \mathrm{H}_{7} \mathrm{~N}_{3} \mathrm{O}_{4} \mathrm{~S}, \mathrm{C}_{7} \mathrm{H}_{7} \mathrm{~N}_{3} \mathrm{O}_{5} \mathrm{~S}, \mathrm{C}_{13} \mathrm{H}_{15} \mathrm{~N}_{3} \mathrm{O}_{6} \\
\mathrm{C}_{13} \mathrm{H}_{15} \mathrm{~N}_{3} \mathrm{O}_{7}\end{array}$ & ${ }^{b} \mathrm{C}_{7} \mathrm{H}_{7} \mathrm{~N}_{3} \mathrm{O}, \mathrm{C}_{7} \mathrm{H}_{5} \mathrm{~N}_{3} \mathrm{O}_{2}, \mathrm{C}_{7} \mathrm{H}_{7} \mathrm{~N}_{3} \mathrm{O}_{2}$ \\
\hline $\begin{array}{l}\text { 1-OH-BTR } \\
\left(\mathrm{C}_{6} \mathrm{H}_{5} \mathrm{~N}_{3} \mathrm{O}\right)\end{array}$ & $\mathrm{C}_{6} \mathrm{H}_{5} \mathrm{~N}_{3} \mathrm{O}$ & $\mathrm{C}_{6} \mathrm{H}_{5} \mathrm{~N}_{3} \mathrm{O}, \mathrm{C}_{6} \mathrm{H}_{5} \mathrm{~N}_{3} \mathrm{O}_{4} \mathrm{~S}, \mathrm{C}_{12} \mathrm{H}_{13} \mathrm{~N}_{3} \mathrm{O}_{7}, \mathrm{C}_{6} \mathrm{H}_{5} \mathrm{~N}_{3} \mathrm{O}_{2}, \mathrm{C}_{6} \mathrm{H}_{5} \mathrm{~N}_{3} \mathrm{O}_{5} \mathrm{~S}, \mathrm{C}_{12} \mathrm{H}_{13} \mathrm{~N}_{3} \mathrm{O}_{8}$ & ${ }^{b} \mathrm{C}_{6} \mathrm{H}_{5} \mathrm{~N}_{3} \mathrm{O}, \mathrm{C}_{6} \mathrm{H}_{5} \mathrm{~N}_{3} \mathrm{O}_{2}$ \\
\hline $\operatorname{XTR}\left(\mathrm{C}_{8} \mathrm{H}_{9} \mathrm{~N}_{3}\right)$ & $\mathrm{C}_{8} \mathrm{H}_{9} \mathrm{~N}_{3}$ & $\begin{array}{l}\mathrm{C}_{8} \mathrm{H}_{9} \mathrm{~N}_{3} \mathrm{O}, \mathrm{C}_{8} \mathrm{H}_{9} \mathrm{~N}_{3} \mathrm{O}_{2}, \mathrm{C}_{8} \mathrm{H}_{7} \mathrm{~N}_{3} \mathrm{O}_{2}, \mathrm{C}_{8} \mathrm{H}_{7} \mathrm{~N}_{3} \mathrm{O}_{3}, \mathrm{C}_{8} \mathrm{H}_{9} \mathrm{~N}_{3} \mathrm{O}_{3} \mathrm{~S}, \mathrm{C}_{8} \mathrm{H}_{9} \mathrm{~N}_{3} \mathrm{O}_{4} \mathrm{~S}, \\
\mathrm{C}_{8} \mathrm{H}_{9} \mathrm{~N}_{3} \mathrm{O}_{5} \mathrm{~S}, \mathrm{C}_{14} \mathrm{H}_{17} \mathrm{~N}_{3} \mathrm{O}_{6}, \mathrm{C}_{14} \mathrm{H}_{17} \mathrm{~N}_{3} \mathrm{O}_{7}\end{array}$ & $\begin{array}{l}{ }^{b} \mathrm{C}_{8} \mathrm{H}_{9} \mathrm{~N}_{3} \mathrm{O}, \mathrm{C}_{8} \mathrm{H}_{9} \mathrm{~N}_{3} \mathrm{O}_{2}, \mathrm{C}_{8} \mathrm{H}_{7} \mathrm{~N}_{3} \mathrm{O}_{2}, \\
\mathrm{C}_{8} \mathrm{H}_{7} \mathrm{~N}_{3} \mathrm{O}_{3}\end{array}$ \\
\hline
\end{tabular}

values of 8 further confirmed the proposed structure. The glucuronidation likely occurred at amines of the tautomeric triazole ring.

Moreover, sulfated 5-Cl-BTR (M5) was detected as [M$\mathrm{H}]^{-}\left(\left[\mathrm{C}_{6} \mathrm{H}_{3} \mathrm{ClN}_{3} \mathrm{O}_{3} \mathrm{~S}\right]^{-}, m / z 231.9589, \Delta m=0.23 \mathrm{ppm}\right)$ at $8.20 \mathrm{~min}$. The main fragment ions for $\mathrm{M} 5, \mathrm{~m} / \mathrm{z} 152.0031$ $\left(\left[\mathrm{C}_{6} \mathrm{H}_{3} \mathrm{ClN}_{3}\right]^{-}\right)$and $88.0206\left(\left[\mathrm{C}_{6} \mathrm{H}_{2} \mathrm{~N}\right]^{-}\right)$, were also noticed for the parent compound 5-Cl-BTR. The mass difference of $79.96 \mathrm{amu}$ from $[\mathrm{M}-\mathrm{H}]^{-}$suggested the loss of a $\left[\mathrm{SO}_{3}\right]$ moiety.

Biotransformation Patterns of 5-Cl-BTR. The potential biotransformation pathway of 5-Cl-BTR comprised of hydroxylated and conjugated bioTPs (Figure 2C). Over the incubation time from 1 to $3 \mathrm{~h}$ (Figure SI-7), a continuous increase in the amount of the hydroxylated bioTPs (M4) was observed. In terms of MS peak area (Figure SI-8), the sulfated hydroxy bioTPs (M2) were the most abundant and formed at a rate 13 times higher than the glucuronidated ones (M1). However, this observation can be linked to different rates of conjugation and also their respective sensitivity in LC-MS analysis.

Predictive Pattern of Other Widely Used BTR Derivatives. BTRs show a wide array of bioTPs formed, a total of 10 metabolites was identified for H-BTH, 14 metabolites for 4-TTR, and 14 metabolites for 5-Cl-BTR. Most of the proposed biotransformation products were identified and structurally elucidated for the first time. Other widely used BTRs such as 1-OH-BTR, 5-TTR, and XTR are structurally close to 4-TTR and 1-H-BTR. Thus, these BTRs may tend to undergo similar metabolic pathways and to generate bioTPs including hydroxylated bioTPs as well as sulfonated and glucuronidated conjugates. Potential metabolism pathways of these three derivatives are proposed and presented in SI.9. Table 1 summarized bioTPs that may need to be taken into account in further biomonitoring studies to assess comprehensive human exposure to BTRs; the proposed bioTPs are based on our experimental results and related predictive results.

Future Research Needs. Our findings showed the importance of investigating the biotransformation products for assessing exposure to xenobiotics. Biotransformation products may constitute a non-negligible amount of the parent compound that is necessary to take into account for a comprehensive exposure assessment study. From that point of view, our study contributes to providing newly identified in vitro metabolites that may be necessary to take into account for a reliable assessment of benzotriazole exposure in future biomonitoring studies (Table 1 ). While in vitro biotransformation products have been investigated in this study, in vivo pharmacokinetics of the identified bioTPs should be further evaluated.

\section{ASSOCIATED CONTENT}

\section{Supporting Information}

The Supporting Information is available free of charge on the ACS Publications website at DOI: 10.1021/acs.est.9b02429.

Biotransformation product identification workflow; Positive Control Phase I; Positive Control Glucuronidation and Sulfonation; Response ratio of individual phase I biotransformation products of H-BTR, 4TTR, and 5-Cl-BTR; Relative abundance of individual biotransformation products of H-BTR, 4TTR, and 5Cl-BTR; Proposed in vitro metabolic pathways for 5TTR, XTR, and 1-OH-BTR; Metabolism of H-BTR, 4TTR e-BTR, and 5-Cl-BTR in human liver microsomes (PDF)

\section{AUTHOR INFORMATION}

\section{Corresponding Authors}

*E-mail: christine.baduel@ird.fr.

*E-mail: adrian.covaci@uanwerpen.be.

ORCID $\odot$

Christine Baduel: 0000-0002-0460-9505

Adrian Covaci: 0000-0003-0527-1136

Notes

The authors declare no competing financial interest.

\section{ACKNOWLEDGMENTS}

Christine Baduel is funded by the French National Research Agency (ANR-16-ACHN-0026). Foon Yin Lai is funded by the Marie Skłodowska-Curie Individual Fellowship (project no. 749845 APOLLO) of the European Commission (Horizon 2020).

\section{REFERENCES}

(1) Benzotriazole - Substance Information - ECHA; https://echa. europa.eu/fr/substance-information/-/substanceinfo/100.002.177 (accessed Sep 25, 2018).

(2) Weiss, J. M.; Simon, E.; Stroomberg, G. J.; de Boer, R.; de Boer, J.; van der Linden, S. C.; Leonards, P. E. G.; Lamoree, M. H. Identification Strategy for Unknown Pollutants Using HighResolution Mass Spectrometry: Androgen-Disrupting Compounds 
Identified through Effect-Directed Analysis. Anal. Bioanal. Chem. 2011, 400 (9), 3141-3149.

(3) Beltoft, V.; Nielsen, E.; Ladefoged, O. Benzotriazole and Tolyltriazole. Evaluation of Health Hazards and Proposal of Health Based Quality Criteria for Soil and Drinking Water; Copenhagen: Danish Ministry of Environmental Protection Agency, 2013; p 28.

(4) Dutch Expert Committee on Occupational Standards. 1,2,3Benzotriazole: Health-Based Recommended Occupational Exposure Limit; Health Council of the Netherlands: The Hague, 2000.

(5) Wang, L.; Zhang, J.; Sun, H.; Zhou, Q. Widespread Occurrence of Benzotriazoles and Benzothiazoles in Tap Water: Influencing Factors and Contribution to Human Exposure. Environ. Sci. Technol. 2016, 50 (5), 2709-2717.

(6) Esteban, S.; Gorga, M.; González-Alonso, S.; Petrovic, M.; Barceló, D.; Valcárcel, Y. Monitoring Endocrine Disrupting Compounds and Estrogenic Activity in Tap Water from Central Spain. Environ. Sci. Pollut. Res. 2014, 21 (15), 9297-9310.

(7) Janna, H.; Scrimshaw, M. D.; Williams, R. J.; Churchley, J.; Sumpter, J. P. From Dishwasher to Tap? Xenobiotic Substances Benzotriazole and Tolyltriazole in the Environment. Environ. Sci. Technol. 2011, 45 (9), 3858-3864.

(8) Xue, J.; Wan, Y.; Kannan, K. Occurrence of Benzotriazoles (BTRs) in Indoor Air from Albany, New York, USA, and Its Implications for Inhalation Exposure. Toxicol. Environ. Chem. 2017, 99 (3), 402-414.

(9) Maceira, A.; Marcé, R. M.; Borrull, F. Occurrence of Benzothiazole, Benzotriazole and Benzenesulfonamide Derivates in Outdoor Air Particulate Matter Samples and Human Exposure Assessment. Chemosphere 2018, 193, 557-566.

(10) Wang, L.; Asimakopoulos, A. G.; Moon, H.-B.; Nakata, H.; Kannan, K. Benzotriazole, Benzothiazole, and Benzophenone Compounds in Indoor Dust from the United States and East Asian Countries. Environ. Sci. Technol. 2013, 47 (9), 4752-4759.

(11) Liu, W.; Xue, J.; Kannan, K. Occurrence of and Exposure to Benzothiazoles and Benzotriazoles from Textiles and Infant Clothing. Sci. Total Environ. 2017, 592, 91-96.

(12) Avagyan, R.; Luongo, G.; Thorsén, G.; Östman, C. Benzothiazole, Benzotriazole, and Their Derivates in Clothing Textiles-a Potential Source of Environmental Pollutants and Human Exposure. Environ. Sci. Pollut. Res. 2015, 22 (8), 5842-5849.

(13) Li, X.; Wang, L.; Asimakopoulos, A. G.; Sun, H.; Zhao, Z.; Zhang, J.; Zhang, L.; Wang, Q. Benzotriazoles and Benzothiazoles in Paired Maternal Urine and Amniotic Fluid Samples from Tianjin, China. Chemosphere 2018, 199, 524-530.

(14) Asimakopoulos, A. G.; Xue, J.; De Carvalho, B. P.; Iyer, A.; Abualnaja, K. O.; Yaghmoor, S. S.; Kumosani, T. A.; Kannan, K. Urinary Biomarkers of Exposure to 57 Xenobiotics and Its Association with Oxidative Stress in a Population in Jeddah, Saudi Arabia. Environ. Res. 2016, 150, 573-581.

(15) Asimakopoulos, A. G.; Wang, L.; Thomaidis, N. S.; Kannan, K. Benzotriazoles and Benzothiazoles in Human Urine from Several Countries: A Perspective on Occurrence, Biotransformation, and Human Exposure. Environ. Int. 2013, 59, 274-281.

(16) Asimakopoulos, A. G.; Bletsou, A. A.; Wu, Q.; Thomaidis, N. S.; Kannan, K. Determination of Benzotriazoles and Benzothiazoles in Human Urine by Liquid Chromatography-Tandem Mass Spectrometry. Anal. Chem. 2013, 85 (1), 441-448.

(17) Zhou, Y.; Liu, H.; Li, J.; Xu, S.; Li, Y.; Zhao, H.; Jin, H.; Liu, W.; Chung, A. C. K.; Hong, Y.; et al. Profiles, Variability, and Predictors of Urinary Benzotriazoles and Benzothiazoles in Pregnant Women from Wuhan, China. Environ. Int. 2018, 121, 1279-1288.

(18) Pluskal, T.; Castillo, S.; Villar-Briones, A.; Oresic, M. MZmine 2: Modular Framework for Processing, Visualizing, and Analyzing Mass Spectrometry-Based Molecular Profile Data. BMC Bioinformatics 2010, 11, 395.

(19) Baduel, C.; Mueller, J. F.; Tsai, H.; Gomez Ramos, M. J. Development of Sample Extraction and Clean-up Strategies for Target and Non-Target Analysis of Environmental Contaminants in Biological Matrices. Journal of Chromatography A 2015, 1426, 33-47. 